\title{
ALL CERAMIC VENEERS: A CASE REPORT
}

\author{
Dileep Soni' ${ }^{1}$, Prateek Agarwal2, Rakesh Jain ${ }^{3}$, Disha Kumar ${ }^{4}$, Bhavana Pareek ${ }^{5}$
}

${ }_{1}^{1}$ Senior Lecturer, Department of Conservative Dentistry and Endodontics, Mahatma Gandhi Dental College \& Hospital, Sitapura, Jaipur. ${ }^{2}$ Senior Lecturer, Department of Oral Maxillo-Facial Surgery, Mahatma Gandhi Dental College \& Hospital, Sitapura, Jaipur. ${ }^{3} P G$. Student, Department of Preventive and Community Dentistry, Mahatma Gandhi Dental College \& Hospital, Sitapura, Jaipur. ${ }^{4} P G$. Student, Department of Paediatric and Preventive Dentistry, Mahatma Gandhi Dental College \& Hospital, Sitapura, Jaipur. ${ }^{5} P G$. Student, Department of Conservative Dentistry and Endodontics Periodontics, Regional Dental College, Guwahati, Assam.

\begin{abstract}
Porcelain veneers are one of the best restorative treatment options available from biological, functional, mechanical and esthetic perspectives. The use of porcelain laminate veneers to solve esthetic and/or functional problems has been shown to be a valid management option, especially in the anterior esthetic zone. The present case reports the case of attrition, anterior teeth in a healthy dentition by means of sectional porcelain veneers simply cemented onto the natural teeth and with minimal tooth preparation. In cases when patients decline orthodontic treatment, adhesively bonded porcelain veneers are a viable treatment option to modify the appearance of tooth position and form, to close diastema or cervical embrasures or to change the tooth shade.
\end{abstract}

\section{KEYWORDS}

Porcelain Veneers, Esthetics.

HOW TO CITE THIS ARTICLE: Soni D, Agarwal P, Jain R, et al. All ceramic veneers: a case report. J. Evolution Med. Dent. Sci. 2016;5(54):3705-3708, DOI: 10.14260/jemds/2016/850

\section{INTRODUCTION}

As early as 1937, Pincus developed thin facings made of airfired porcelain. He attached these thin labial porcelain veneers temporarily with denture adhesive powder to enhance the appearance of the Hollywood actors for their close-up photographs. Pincus was fully aware of the importance of the "Hollywood smile" as an integral part of the image and public opinion. These facings presented a viable option to the full crown for the actors who needed to temporarily change their smile, yet they possessed very little strength, and the technology necessary to provide a permanent means of attaching the veneers to tooth structure was lacking. Porcelain veneers are a recent and very exciting development in the dental armamentarium. At the present time, many dentists are accomplishing veneers as a routine procedure. They have become a major part of the so-called "Esthetic dentistry" movement. They enable the dentist to change the appearance, size, colour, spacing and to a minor extent the positioning of the teeth. ${ }^{1,2}$

\section{CASE REPORT}

A 27-year-old man presented with complaints about the shape and size of her maxillary anteriors, and he wanted to treat mild attrition case (Fig. 1). After discussion with the patient, it was decided that porcelain veneers would be placed on teeth 11 and 21 . We wanted to apply a conservative protocol to fulfil the patient's wishes.

Once it has been determined that a patient is a good candidate for Porcelain Laminate Veneers treatment, it is imperative that a complete oral examination is completed to determine the appropriateness of veneer therapy. ${ }^{3}$

Financial or Other, Competing Interest: None.

Submission 11-05-2016, Peer Review 22-06-2016,

Acceptance 27-06-2016, Published 07-07-2016.

Corresponding Author:

Dr. Dileep Soni,

B-401, Maharaja Apartment,

Opt. Chinkara Canteen Bani Park,

Jaipur-302016.

E-mail: dileep01.soni@gmail.com

DOI: $10.14260 /$ jemds $/ 2016 / 850$

\section{The Records Appointment consists of}

1. Pre-operative photographs.

2. Charting of existing restorations.

3. Complete hard and soft tissue evaluation.

4. Upper and lower impressions for study model fabrication.

5. Intra- and extra-oral photography.

6. Interview patient regarding goals and expectations. 4

This information is critical for the dentist to evaluate the appropriateness of the proposed treatment, but it also provides the critical information to develop the treatment plan and the treatment sequence.

After thorough examination, impressions for diagnostic models were made in irreversible hydrocolloid. The models were studied to decide the shape and size of the restorations with help of a diagnostic wax up. And the treatment planning was discussed with the patient.

\section{Tooth Preparation for Veneers}

The preparations must fulfil the following four basic principles if perfect, functional, biological and aesthetic integration is to be achieved: stabilization, reinforcement, retention and adhesion. Relying on adhesion without taking the other three factors into account generally leads to immediate or ultimate failure. Preserving as much of the natural enamel as possible, although desirable, must never jeopardize the planned restoration by minimizing the preparation. Enamel reduction requires special instrumentation that involves the four surfaces of the teeth. 5,6,7

Once the tooth preparation was completed (Fig. 2) shade selection was done using Vitapan classical shade guide (Vita Zahnfabrik, Germany). Final shade was selected and impression was made using single step double mix technique using addition silicone putty and light body consistency (Dentsply Aquasil) impression technique, a prefabricated perforated tray was loaded with putty and at the same time light body material was syringed around the prepared teeth to record the fine details and the previously loaded tray was inserted in the mouth to make impressions. The impression 
was poured in type IV gypsum product and die preparation was done. Meanwhile, the provisional restoration was fabrication. The porcelain veneers (IPS e.max) were laboratory fabricated (Fig. 3, 4, 5, 6). The trail of the veneer was done for the shade, fit, marginal adaptation, shape, size, symmetry and contacts. Patient's approval was obtained at the time of try in. Then these were cemented on to the prepared tooth using self-curing resin based luting cement (Multilink Automix, Ivoclar Vivadent) under proper isolation excess cement was removed with a plastic scaler (Fig. 7).

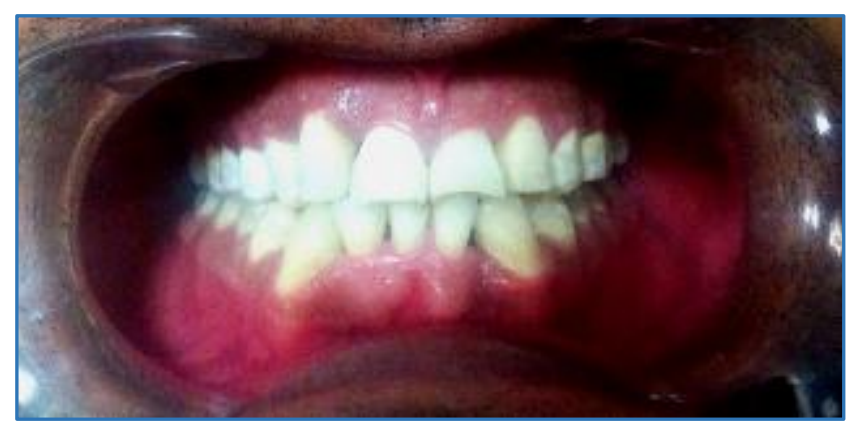

Fig. 1: Pre-Operative Image

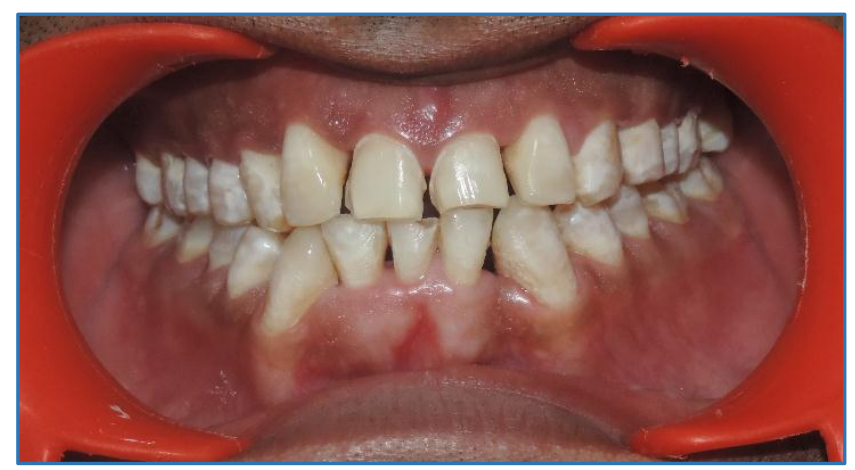

Fig. 2: After Tooth Preparation

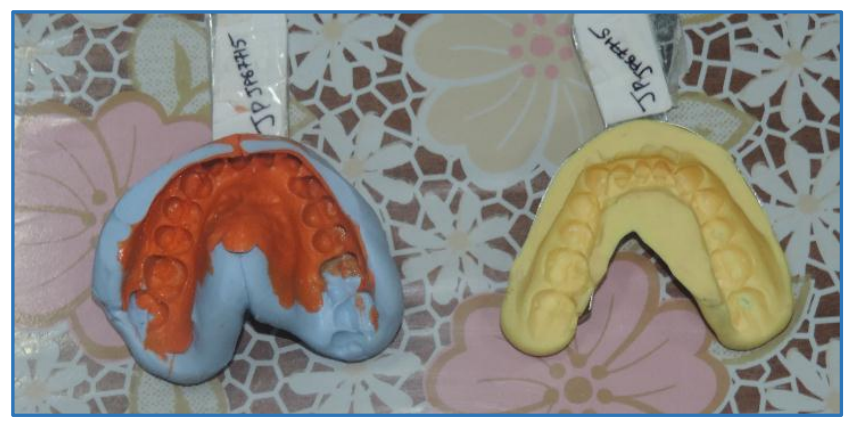

Fig. 3: Impression

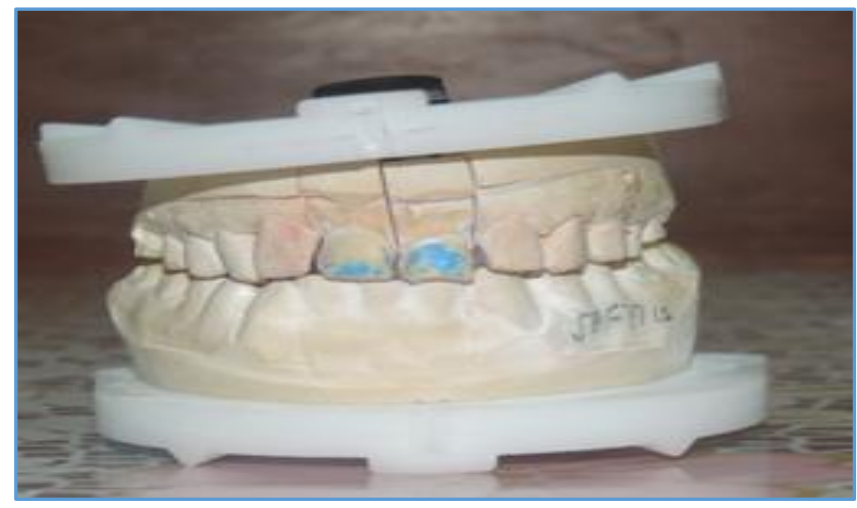

Fig. 4: After Cast Fabrication of All Ceramic Veneer

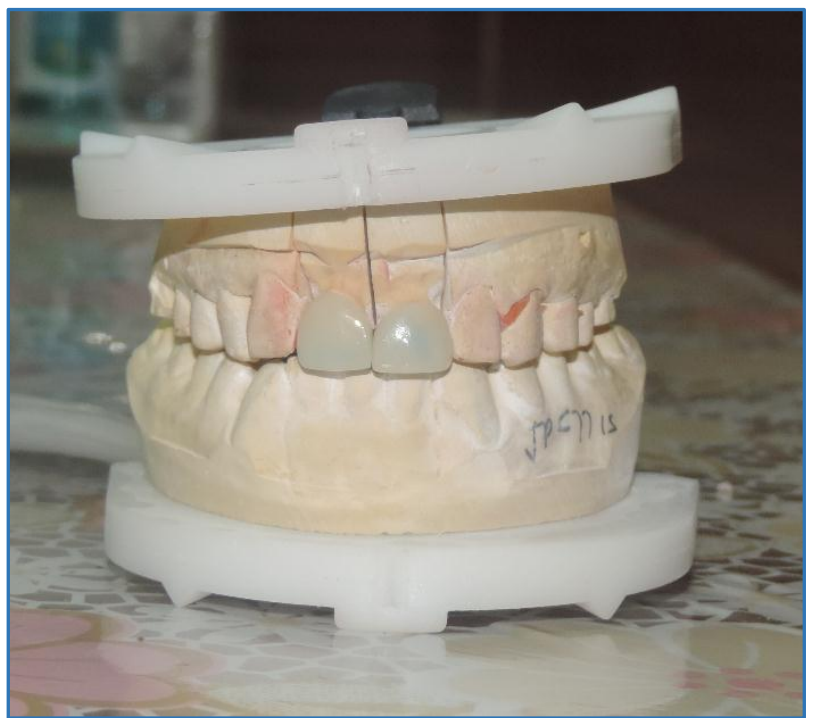

Fig. 5: All Ceramic Veneer on Cast-Labial View

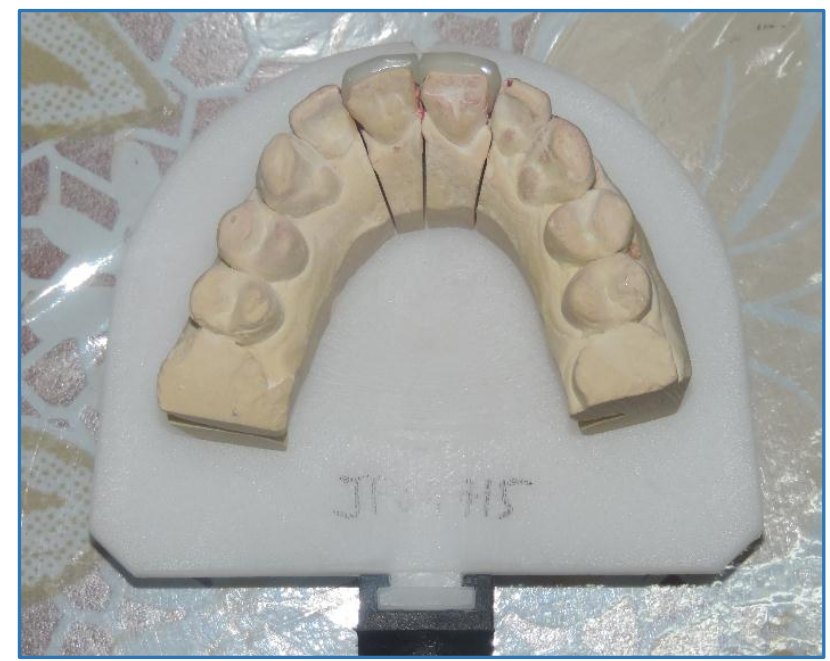

Fig. 6: All Ceramic Veneer on Cast-Lingual View

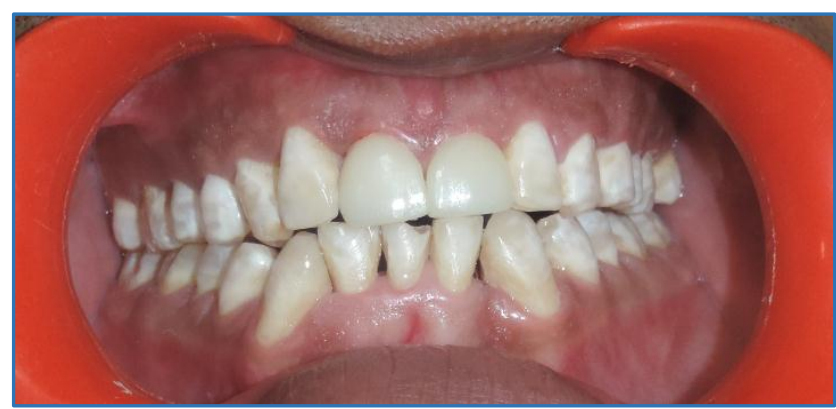

Fig. 7: Post-Operative Image

\section{DISCUSSION}

\section{Instrumentation}

It is the shape of the instrument that determines the profile of the preparation. TPS kits consist of eight burs, enabling veneer preparations to be accomplished in total safety. The laminate veneer preparation kit (Fig. 6) comprises.

- Two instruments (Gauges TFC1 and TFC2) to monitor labial reduction.

- Two instruments (TFC3 and TFC4) for reduction of enamel and margins. 
- Two instruments (TFC5 and TFC6) for occlusal reduction.

- $\quad$ Two finishing instruments (TFC7 and TFC8).

Brasseler TPS tool kit instruments for preparation and finish of ceramic veneers. The advantage of this kit lies in simplifying preparation by plain codifying and offering a limited number of instruments.

The two 'Depth-cutter' instruments (TFC1, TFC2) serve to guide, visualize and in particular quantify enamel reduction. In addition, margins can be plotted, owing to the rounded tip. The authors consider it dangerous to gauge reduction in enamel depth of between 0.1 and $0.5 \mathrm{~mm}$ without depth guide, who also recommends two instruments based on the same principle in the laminate veneer preparation kit shares the same concern. Specifically designed porcelain laminate veneer preparation and finishing kits ease the whole procedure, since the chosen burs can be used in step-by-step. Other techniques exist for monitoring depth, such as those advocated before the introduction of penetration gauges. A spherical diamond bur (Komet H01 314 009) traces out a 0.4 - $0.5 \mathrm{~mm}$ groove as a guide in the same way as Lusco's enamel depth cutter (A small diamond disc with a smooth stop). Uniform enamel preparation must result in an average tissue reduction of $0.5 \mathrm{~mm}$. One may, in cases of extreme discoloration, be inclined to increase the depth to $0.7-0.8 \mathrm{~mm}$. A depth below $0.3 \mathrm{~mm}$ is not recommended (Goldstein).

- Enamel provides a better seal and more effectively diminishes marginal leakage than a finish line in either cement or glass ionomer.

- Due to relatively thin enamel in gingival half, the desired reduction in that area is $0.3 \mathrm{~mm}$.

- Minimal thickness of porcelain laminate veneer is 0.3-0.5 $\mathrm{mm} .8,9$

\section{CEMENTATION}

Cementation procedures for bonding veneers - The longevity and success of indirect restorations are influenced by patient and operator. The patient dictates oral hygiene, diet and functional habits.

- The operator manages tooth preparation, impression and cementation. Cementation is a crucial step in the process of ensuring the retention, marginal seal and durability of indirect restorations.

- Cementing procedures are either adhesive or nonadhesive. Adhesive cementation involves the use of an agent to promote bonding of the restorative material to the substrate; it is a combination of adhesive chemical bonding and micromechanical interlocking.

- Non-adhesive (Conventional) cementation involves the use of a luting agent to fill the space between the restoration and the natural tooth and relies solely on micromechanical retention. ${ }^{10,11,12}$

\section{STEP 1=IPS e.max Restoration Conditioning}

- Etching Restoration - Apply IPS Ceramic Etching Gel (5\% HF Acid) for 20 seconds to bonding surface of the restoration. (This step provides an increased surface area, micromechanical retention and a clean surface for adhesive cementation.)

- $\quad$ Rinse thoroughly and air dry.
- The clinician places silane over the etched surface to increase the wettability of the resin cement and to interact chemically with both the resin matrix and the hydroxylated porcelain surface.

Both etching and silanation are recommended, as some investigators have reported higher veneer failure rates when ceramic is air abraded and silanated, but not etched with $\mathrm{HF}$ acid. The surface is best cleaned with CoJet (ESPE). The 30micron thickness of the material will still let the 80-microns of the adhesive (OptiBond) that has been applied at the preparation stage stay in place. Care should be taken not to cause any bleeding of the gingiva. ${ }^{11}$ The gingiva can easily be re-contoured with a diode laser (Biolase), if needed.

- Priming Restoration - Apply Monobond Plus Universal Primer to the bonding surface of the restoration. Allow to react for 60 secs, completely air dry.

\section{STEP 2-Tooth Conditioning}

- $\quad$ Etching Tooth - Apply Total Etch 37\%, Phosphoric Acid etching gel, ( 15 secs on dentin, 30 secs on enamel) Rinse and dry leaving prepared surface moist.

- Priming Tooth - Apply bonding agent to moist preparation.

\section{STEP 3-Cementation}

- Mix and dispense cement into restoration.

- Adhesive cementation to enamel or dentin requires the use of an adhesive system followed by application of a resin cement.

- Adhesive systems can be either self-etching or total etching. 11,12

\section{STEP 4-Clean Up}

- After seating, light cure each quarter surface for 1-2 secs. The cement will achieve a gel-like consistency for easy clean-up.

\section{FINISHING AND POLISHING}

Upon completion of the cementation, there will be some excess resin cement that will need to be removed. Initial removal from the gingival and the interproximal can be achieved with a \#12 scalpel blade.

The use of modern dental materials and a justifiable reliance on the predictable artistic abilities of the dental technologist allows the fabrication of both aesthetic and durable restorations. ${ }^{13}$

\section{CONCLUSION}

A current best practice in use of porcelain laminate veneer for creating an aesthetic change is to use a very minimal, if not non-invasive, tooth preparation that is restored with a very thin piece of porcelain. ${ }^{1}$ Porcelain Laminate Veneers are a versatile restoration that can be a solution to many problems, but they may not always be the best solution. Good judgment and great communication are part of the keys to success with Porcelain Laminate Veneer therapy. ${ }^{2}$

\section{REFERENCES}

1. Christensen GJ. Veneering of teeth. State of the arts. Dent Clin North Am 1985;29(2):373-91.

2. Radz GM. Minimum thickness anterior porcelain restorations. Dent Clin N Am 2011;55(2):353-70. 
3. Christensen GJ. Veneering teeth with ceramic has become a major part of esthetic dentistry, and many general dentists provide this service. JADA 2006:1720-4.

4. Calamia JR, Calamia CS. The etched porcelain veneer technology has demonstrated long term clinical success. Dent Clin N Am 2007;51:399-417.

5. Freedman GA, McLaughlin GL. In: Hacke GDC (ed). Colour atlas of porcelain laminate veneers. $1^{\text {st }}$ ed. St. Louis: Ishiyaku Euro America Inc 1990.

6. Goldstein RE. Etched porcelain restorations veneers \& inlays/onlays. $2^{\text {nd }}$ ed. Esthetics in dentistry. Ch 14, 1998:339-42.

7. Reshad M, Cascione D, Magne P. The demonstrations that how a clinician can objectively overcome some of the barriers associated with providing patients with predictable esthetics, in a mutually satisfactory manner. J Prosthet Dent 2008;99(5):333-9.
8. Matinlinna JP, Vallittu PK. Bonding of resin composites to etchable ceramic surfaces: an insight review of the chemical aspects on surface conditioning. J Oral Rehabil 2007;34(8):622-30.

9. Cekic I, Ergun G, Lassila LV, et al. Ceramic-dentin bonding: effect of adhesive systems and light-curing units. J Adhes Dent 2007;9(1):17-23.

10. Kanehira M, Finger WJ, Hoffmann M, et al. Compatibility between an all-in-one self-etching adhesive and a dualcured resin luting cement. J Adhes Dent 2006;8(4):22932.

11. Manso AP, Silva NR, Bonfante EA, et al. Cements and adhesive for all-ceramic restorations. Dent Clin N Am 2011;55(2):311-32.

12. Pegoraro TA, da Silva NR, Carvalho RM. Cements for use in aesthetic dentistry. Dent Clin North Am 2007;51(2):453-71.

13. Radovic I, Monticelli F, Goracci C, et al. Self-adhesive resin cements: a literature review. J Adhes Dent 2008;10(4):251-8. 